\title{
Particulate Matter Concentrations in the Vicinity of an Incinerator
}

\section{Kristine Walungama Endjambi', Onjefu Sylvanus Ameh², Nnenesi Kgabi3 ${ }^{3}$ Innocent Maposa4, Ndinomholo Hamatui ${ }^{1}$}

${ }^{1}$ Department of Health Sciences, Namibia University of Science and Technology, Windhoek, Namibia

${ }^{2}$ Department of Natural and Applied Sciences, Namibia University of Science and Technology, Windhoek, Namibia

${ }^{3}$ Department of Civil and Environmental Engineering, Namibia University of Science and Technology, Windhoek, Namibia

${ }^{4}$ Department of Mathematics and Statistics, Namibia University of Science and Technology, Windhoek, Namibia

Email: nhamatui@nust.na

How to cite this paper: Endjambi, K.W., Ameh, O.S., Kgabi, N., Maposa, I. and Hamatui, N. (2016) Particulate Matter Concentrations in the Vicinity of an Incinerator. Journal of Geoscience and Environment Protection, 4, 88-100.

http://dx.doi.org/10.4236/gep.2016.412007

Received: October 13, 2016

Accepted: December 5, 2016

Published: December 8, 2016

Copyright () 2016 by authors and Scientific Research Publishing Inc. This work is licensed under the Creative Commons Attribution International License (CC BY 4.0)

http://creativecommons.org/licenses/by/4.0/

\begin{abstract}
Incineration is an effective way of health care waste management, but it is also a source of air pollution. Thermal decomposition of organic and inorganic waste during incineration releases a large concentration of air pollutants such as $\mathrm{CO}, \mathrm{SO}_{2}$, NOx, $\mathrm{CO}_{2}$ and particulate matter (PM). A cross sectional-descriptive study was conducted to determine the short-term variations in PM concentrations across various areas in the vicinity of a local incinerator in Windhoek, Namibia. XRF Qualitative analysis method was used to determine the elemental composition of fallout dust concentration from six study areas/stations in the vicinity of a local incinerator. Single bucket fallout monitors were deployed following the American Society for Testing and Materials standard method for collection and analysis of dust fallout to determine the elemental composition of fallout dust. Real-time PM concentration trends were also recorded using a portable Micro dust Pro Real-time Dust Monitor for $\mathrm{PM}_{10}$ at a height of $2.2 \mathrm{~m}$ above the ground. High PM concentration peaks were observed in the morning and afternoon hours at varying points. The fallout dust rate ranged between highest $1839.3 \mathrm{mg} / \mathrm{m}^{2} /$ day at sampling Point 4 and lowest 711 $\mathrm{mg} / \mathrm{m}^{2} /$ day at sampling Point 2 . The XRF analysis revealed the presence of toxic elements and crustal elements in order of decreasing abundance: $\mathrm{Mn}>\mathrm{Zn}>\mathrm{Cr}>\mathrm{V}>$ $\mathrm{Zr}>\mathrm{Sr}>\mathrm{Pb}>\mathrm{Ni}$ and $\mathrm{SI}>\mathrm{K}>\mathrm{Fe}>\mathrm{Ti}>\mathrm{Ca}>\mathrm{Al}>\mathrm{P}$ respectively. Highest elemental composition concentrations were found at sampling location in the vicinity of the incinerator and in industrial area.
\end{abstract}

\section{Keywords}

Particulate Matter, Fallout Dust, Concentration, Incinerators, Windhoek 


\section{Introduction}

Incineration is an effective way of healthcare waste management, but at the same time, it is also a source of air pollution. The process of incineration remains a highly controversial topic mainly due to the risk of air pollution associated with the process [1]. Thermal decomposition of organic and inorganic waste during incineration releases a large concentration of air pollutants such as $\mathrm{CO}, \mathrm{SO}_{2}, \mathrm{NOx}, \mathrm{CO}_{2}$ and particulate matter (PM). Amongst other pollutants, the PM has been pronounced as the most harmful ambient air pollutant; hence its adverse effect on human health [2] and among the problems of concern in great cities is the increase in industrial activities and vehicular activities which increase emissions of pollutants such as PM [3]. Earlier studies on urban ambient air quality have linked PM to several health consequences such as: cerebrovascular disease (stroke), respiratory infections, cardiopulmonary disorders, ischemic heart disease, mortality and reduction in health, life expectancy, hospital admission due to cardiovascular and respiratory diseases, asthma attacks, acute bronchitis and frequency health care visits [4] [5]. In addition to increasing the risk of developing a wide range of respiratory diseases and heart diseases, PM is considered carcinogenic to human [6]. There are currently no scientifically defined safe levels of PM concentration exposure, as health effects have been observed at both low and high levels of particulate matter below the World Health Organization (WHO) guidelines [7]. The impact of particulate pollutant exposure to human health is said to increase with the PM level, period and frequency of exposure [4] [7]. The toxic effects of PM have been affirmed to depend greatly on the chemical constituency of the particles. Therefore a better understanding of the chemical constituents of ambient particles is fundamental in bridging the knowledge gap between the air quality and its health effects [8].

The concentration of particulate matter in an area over a period of time is not static; it differs spatially and is temporal depending on various natural and anthropogenic characteristics of the area. Evidence suggests that, there is a correlation between air pollutant concentration level and environmental factors such as topography, meteorological factors such as wind speed, wind direction, humidity and temperature and season [9] [10] [11]. Evidence from earlier studies affirmed that PM concentrations are highly concentrated in areas close to the emitting source and concentration decrease from the source [12]. Daily trends in pollutants concentration have also been observed. Pollutants from anthropogenic sources are often at peak in the morning hours and early night hours as a result of vehicular and industrial activities [10]. This concept is factual for primary particulate pollutants but different for secondary pollutants whose concentrations depend on sunlight (radiant energy) as well as the presence and conversion of pollutants into PM i.e. sulphate and nitrate particles which are generated by conversion from primary sulphur and nitrogen oxide emissions and secondary organic aerosol from VOCs emissions also affect the concentration of PM in the ambient air [13]. Photochemical reaction is partially responsible for particulate matter reaching peak levels during afternoon hours and a decline in concentration after hours hence reduction in solar intensity [14]. 
In an effort to mitigate PM pollutants and its impact on both human health and the environment, WHO established various air quality guidelines to offer guidance to countries in reducing the health impacts of air pollution, and encouraged for ambient air quality monitoring in order to safeguard public health. Despite the fact that about $25.9 \%$ of the Windhoek households do not have access to electricity for cooking and heating, and that industrial developments have increased continually for the past ten years, there are about 380 registered vehicles per 1000 people in the city; and despite the need to quantify air quality as argued by researchers there are no published scientific studies apart from sourced data from project-specific air quality studies, usually undertaken as specialist studies in Environmental Impact Assessments (EIA); nor any laws and regulations for monitoring of air quality in Namibia [15]. Windhoek lacks baseline data on particulate pollution associated with industrial emissions such as the Katutura State Hospital incinerator and Van Eck Power station [16]. The study objective was to assess the short term PM concentration levels; determine and compare the daily PM variation at various points in the vicinity of the incinerator and also characterize the elemental composition for the fallout dust at such points.

\section{Methodology}

\subsection{Background of Study Area}

Windhoek is the capital city of Namibia, it is situated almost at the epicentre, it is lies between $22^{\circ} 34^{\prime} 12^{\prime \prime S}$ and $17^{\circ} 5^{\prime} 1$ "E. It is located between the Khomas Highlands, Eros and Auas Mountains, in the Khomas region. It is about $1680 \mathrm{~km}$ above the sea level and $650 \mathrm{~km}$ north of the Orange River and $360 \mathrm{~km}$ towards Atlantic seashore. The selected study area is situated on the northern part of Windhoek; inclusive is the area in the radius of $1 \mathrm{~km}$ from the local incinerator. The area is centred by road network, the busy independence avenue road that link Katutura location to City Centre and the Western Bypass. Sources of air pollution in the vicinity of the area includes, industrial activities, residential activities, power plant, diesel power station, mobile sources, natural sources (e.g. wind), and a hazardous medical waste incinerator being the point source. The diagram below gives an indication of the six points (starred and numbered 1 - 6) where study monitoring and sampling took place and the location of the incinerator (see Image 1).

\subsection{Sampling Method}

Sampling sites were purposively selected, whereby points which met prescribed criterion such as: the safety of the place to place monitoring station; the direction of the sampling from the local incinerator; city zoning; topography and location of nearby sources of pollution were considered. At least one sampling station was selected on the four main directions from the incinerator and at least one station in each of the three cities zoning (industrial, residential and institutional zoning). Six sites were selected (see Table 1) whereby point 1 and 2 were at boarding schools, point 3 and 5 in residential area, point 4 at an institutional zoned area, church, and point 6 in industrial area. 


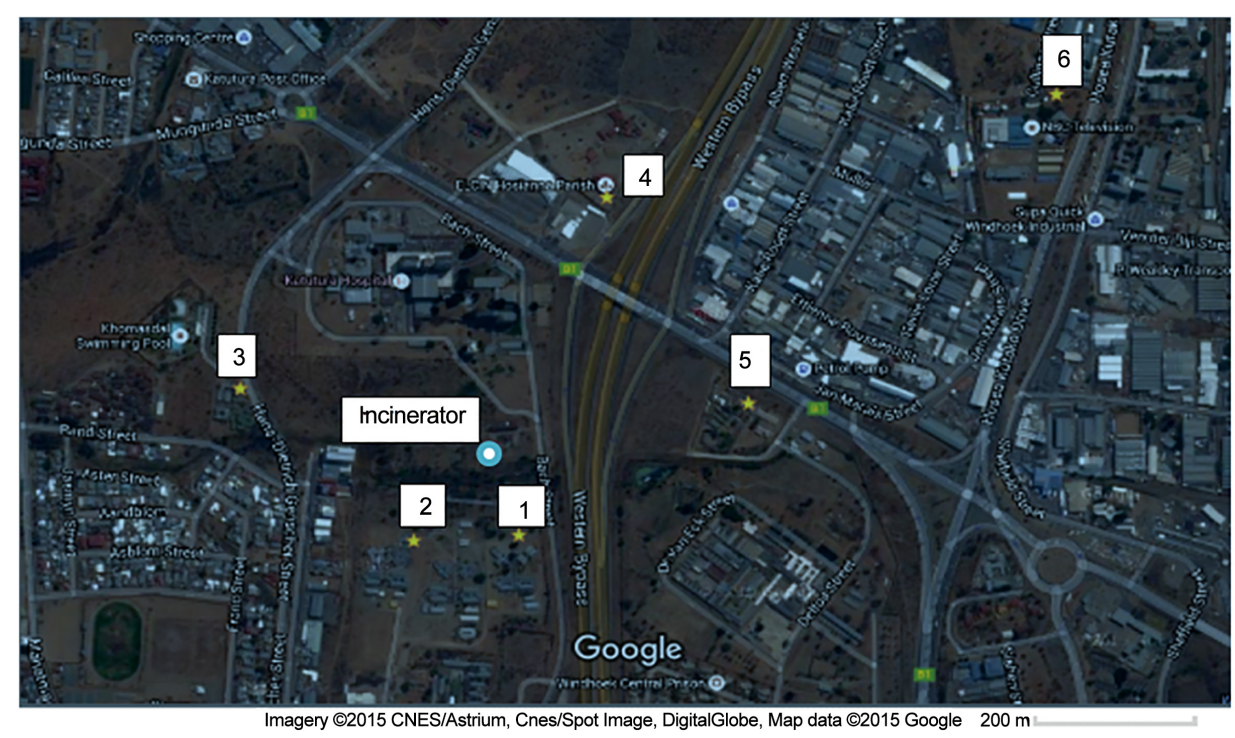

Image 1. The six selected sampling sites (marked with stars) retrieved from: https://www.google.com.na/maps/@-22.5441497,17.0740555,15z.

Table 1. The six selected sampling sites and their geographical characteristics.

\begin{tabular}{|c|c|c|c|}
\hline Station & Coordinates & Elevation & Site description \\
\hline Station 1 & $\begin{array}{l}\mathrm{S} 22^{\circ} 31^{\prime} 20.7^{\prime \prime} \\
\mathrm{E} 17^{\circ} 04^{\prime} 00.2^{\prime \prime}\end{array}$ & $1629 \mathrm{~m}$ & $\begin{array}{l}\text { A boarding school (residential area) } 187 \mathrm{~m} \text { South of } \\
\text { incinerator and } 58.66 \mathrm{~m} \text { from Bach Street. }\end{array}$ \\
\hline Station 2 & $\begin{array}{l}\mathrm{S} 22^{\circ} 32^{\prime} 21.1^{\prime \prime} \\
\mathrm{E} 17^{\circ} 03^{\prime} 53.5^{\prime \prime}\end{array}$ & $1644 \mathrm{~m}$ & $\begin{array}{l}\text { A boarding school (residential area), } 226.58 \mathrm{~m} \text { South } \\
\text { west of incinerator. }\end{array}$ \\
\hline Station 3 & $\begin{array}{l}\mathrm{S} 22^{\circ} 32^{\prime} 11.9^{\prime \prime \prime} \\
\mathrm{E} 17^{\circ} 03^{\prime} 42.6^{\prime \prime}\end{array}$ & $1646 \mathrm{~m}$ & $\begin{array}{l}\text { A residential area, } 474 \mathrm{~m} \text { West of incinerator and } 28.2 \\
\mathrm{~m} \text { from the road. }\end{array}$ \\
\hline Station 4 & $\begin{array}{l}\text { S } 22^{\circ} 31^{\prime} 59.7^{\prime \prime} \\
\text { E } 17^{\circ} 04^{\prime} 05.7^{\prime \prime}\end{array}$ & $1650 \mathrm{~m}$ & $\begin{array}{l}\text { An institutional zoned area, church, } 531 \mathrm{~m} \text { North of } \\
\text { incinerator; } 48.6 \mathrm{~m} \text { and } 87.9 \mathrm{~m} \text { from Bi and Western } \\
\text { Bypass respectively. }\end{array}$ \\
\hline Station 5 & $\begin{array}{l}\mathrm{S} 22^{\circ} 32^{\prime} 12.5^{\prime \prime} \\
\mathrm{E} 17^{\circ} 03^{\prime} 14.7^{\prime \prime}\end{array}$ & $1640 \mathrm{~m}$ & $\begin{array}{l}\text { A residential area, } 488 \mathrm{~m} \text { West of incinerator } 49.82 \mathrm{~m} \\
\text { and } 119.2 \mathrm{~m} \text { from independence avenue road and petrol } \\
\text { station respectively, few meters away from industrial } \\
\text { area. }\end{array}$ \\
\hline Station 6 & $\begin{array}{l}\mathrm{S} 22^{\circ} 31^{\prime} 53.7^{\prime \prime} \\
\mathrm{E} 17^{\circ} 04^{\prime} 34.2^{\prime \prime}\end{array}$ & $1624 \mathrm{~m}$ & $\begin{array}{l}\text { Industrial zoned area } 1.21 \mathrm{~km} \text { North west of incinerator } \\
\text { and } 72 \mathrm{~m} \text { from Hosea Kuutako road located in } \\
\text { Southern Industral Area. }\end{array}$ \\
\hline
\end{tabular}

\subsection{Data Collection Methods}

\subsection{1. $\mathrm{PM}_{10}$ Real Time Monitoring}

Particulate sampling and measurement was done using a portable Microdust Pro Realtime Dust Monitor serial number 1,749,391 for $\mathrm{PM}_{10}$ at a height of $2.2 \mathrm{~m}$ above the ground, a preferable sampling height when one have to consider the impact of air pollution to human health and the area in which people are most active from the ground. The instrument was set to collect $\mathrm{PM}_{10}$ at density of 25,000 $\mathrm{mg} / \mathrm{m}^{3}$ and record 60 
seconds average $\mathrm{PM}_{10}$ concentration at a logging interval of one minute for 8 hours, from $08 \mathrm{~h} 00$ to $16 \mathrm{~h} 00$. Span Calibration was done every day before assessment to eliminate or reduce bias in an instrument's readings over a range for all continuous values. The monitor gives a graphical representation of particulate concentration trends and measurements were later downloaded into a Casella Insight Data Management Software, which provides a real-time display of particulate concentration level measured. Measurements were collected twice at each sampling station.

\subsubsection{Fallout Dust Monitoring}

Fallout buckets were used to collect fallout dust following the American Society for Testing and Materials standard method for collection and analysis of dust fallout (ASTM D1739) [17]. This method employs a simple device consisting of a cylindrical container half-filled with de-ionized water exposed for one calendar month. In the study, six 5-liter buckets containing 4 litters of de-ionized water treated with biocide to prevent fungal growth and located 2.2 meters above the ground was exposed for two week only because of high evaporation rate in Windhoek during spring season. The buckets were exposed for two weeks and the method was carried out for four consecutive weeks in order to obtain the average fallout dust concentration at the sites. After returning the buckets to the laboratory, the contents of the buckets was filtered out onto $110 \mathrm{~mm}$ pre-weighted ashless filter papers (Double Rings Filter Papers 102) using a Buchner Funnel connected to a diaphragm vacuuming pump. The filter papers were dried up in a cupboard overnight and post-weighed. Elemental composition analysis was done using X-Ray Fluorescence (XRF) analysis method, whereby the dust sample was illuminated by an intense X-ray energizing any present atoms which in turn emits $\mathrm{X}$-rays along a spectrum of wavelengths characteristic of the types of atoms present in the sample, this wavelength are then amplified and analysed using computer software.

\section{Results and Discussion}

\section{1. $\mathrm{PM}_{10}$ Real time Measurements}

The daily PM concentration measured at sampling points varied per day of sampling and from point to point and fluctuated throughout the sampling period. The result on PM concentration over the entire sampling period is shown in Figures 1-6. The average particulates concentration recorded at all sampling points were between minimum and maximum concentrations of $1.791 \mathrm{mg} / \mathrm{m}^{3}$ and $4.271 \mathrm{mg} / \mathrm{m}^{3}$ respectively. A common trend of $\mathrm{PM}_{10}$ concentration variation was observed at sampling point 1, 2, 3 and 5 as indicated in Figure 1-3 and Figure 5,. Whereby a gradual increase in average PM concentration from morning until it reaches maximum peaks levels around noon and afternoon and afterward concentrations decrease progressively until the end of the sampling period.

Sampling Point 4 was an exception as high peaks and average concentration above $2.5 \mathrm{mg} / \mathrm{m}^{3}$ were recorded between $08 \mathrm{~h} 00$ and $10 \mathrm{~h} 00$. A slightly constant PM concentration below $2.5 \mathrm{mg} / \mathrm{m}^{3}$ was observed at point 4 throughout the sampling period. Whe- 
reas at station 6, continuous increase in PM concentration throughout the sampling was recorded in all the days, but a peak level was recorded at 08 h00 in day 1 , reaching concentration above $2.5 \mathrm{mg} / \mathrm{m}^{3}$ during the first and the second last hour of measurement.

High peaks in PM concentration was observed in the morning hours, i.e. at Point 6 (as indicated in Figure 6) day 1 and Point 4 (Figure 4) all the two days, can be predominantly attributed to a high number of vehicles movement (rush hours) in two directions since the points are close to the road [10] [18].

Random fluctuation in particulates concentrations levels at all sampling points is an indication of the presence of non-point source of pollution in the environment. Fluctuation and various peaks concentration recorded throughout the sampling session may

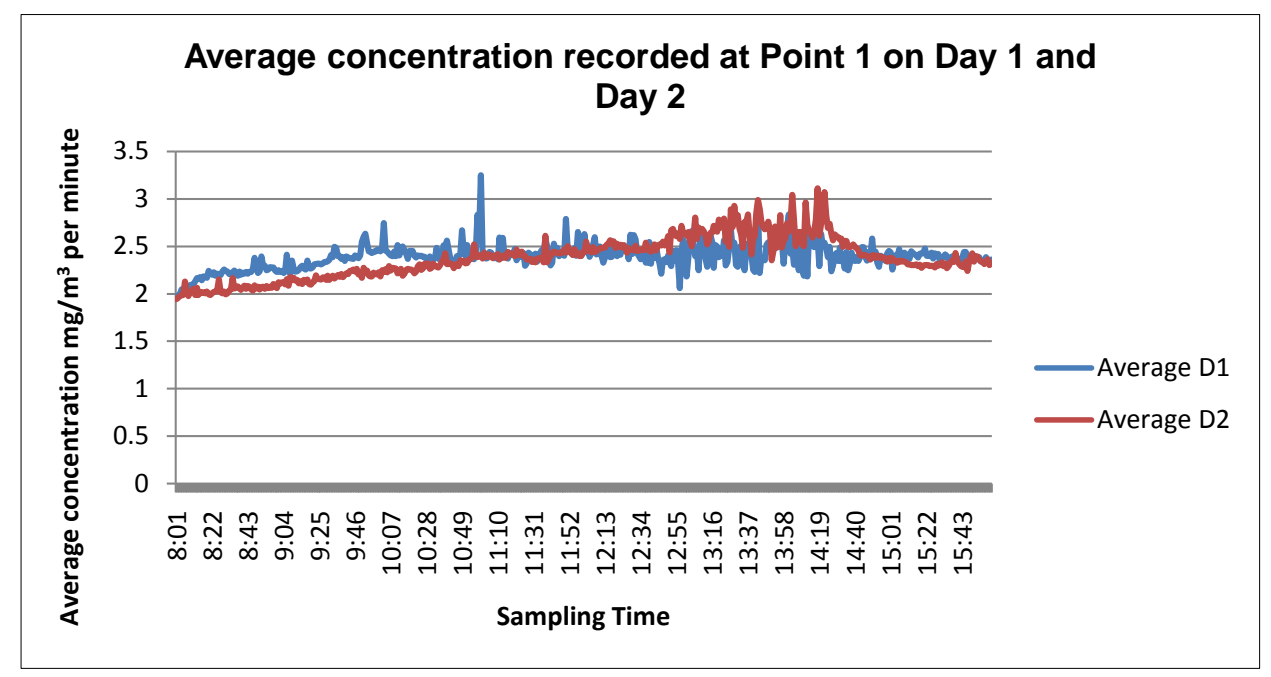

Figure 1 . The measured average PM concentration at sampling point 1 in the vicinity of incineration plant.

Average concentration recorded at Point 2 on Day 1 and Day 2

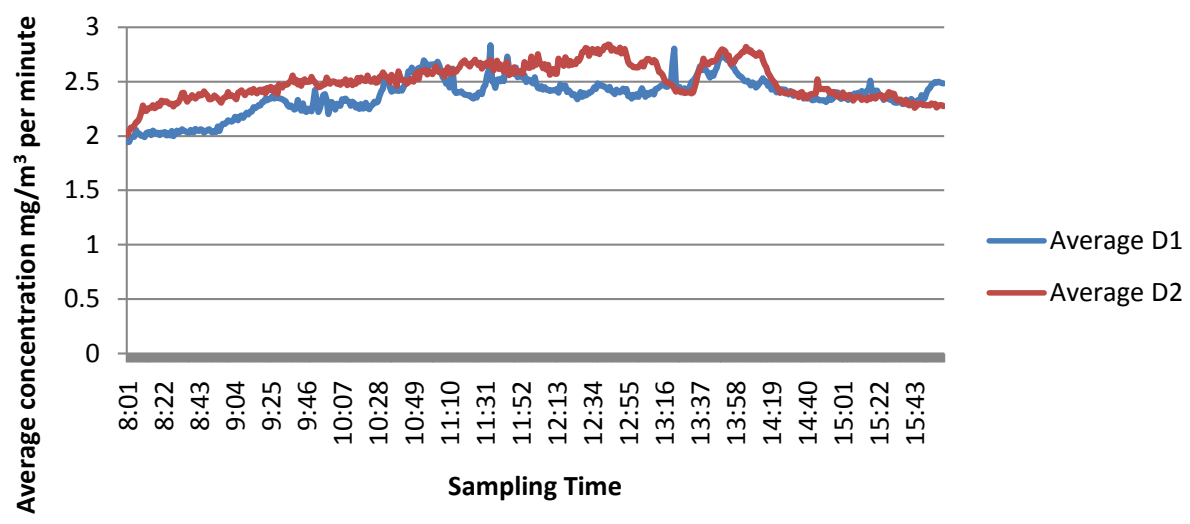

Figure 2. The measured average PM concentration at sampling point 2 in the vicinity of incineration plant. 
Average concentration recorded at Point 3 on Day 1 and Day

2

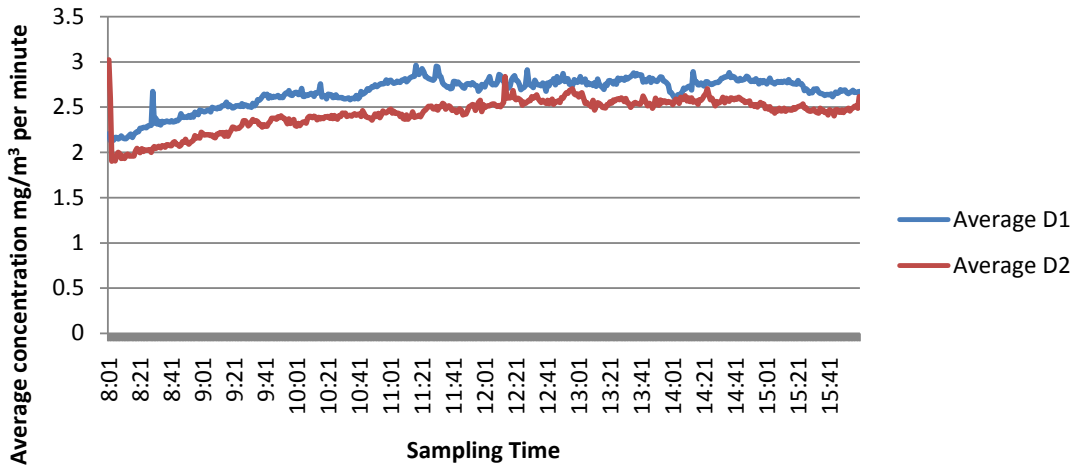

Figure 3. The measured average PM concentration at sampling point 3 in the vicinity of incineration plant.

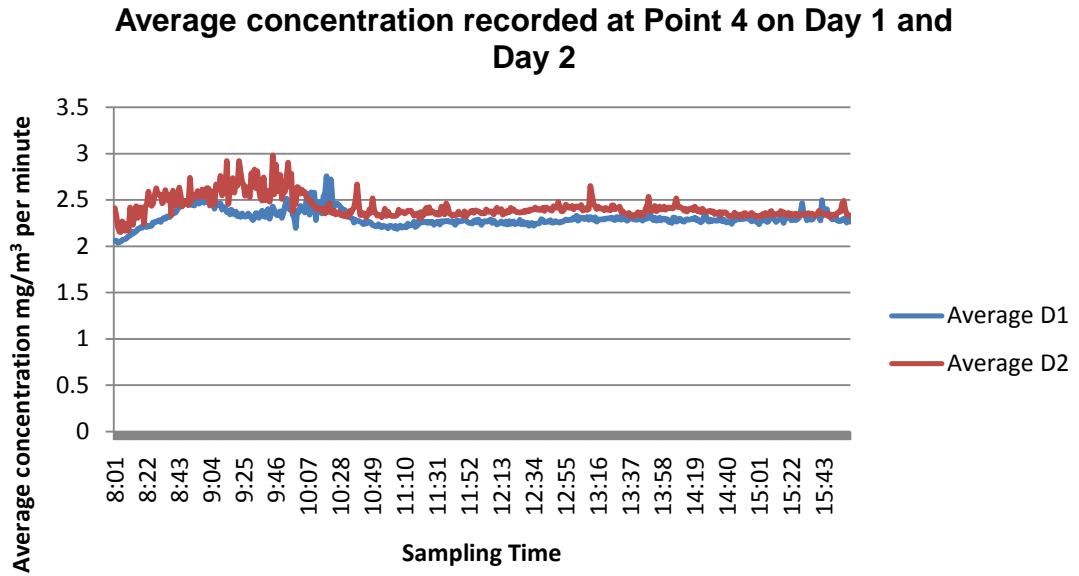

Figure 4. The measured average PM concentration at sampling point 4 in the vicinity of incineration plant.

Average concentration recorded at Point 5 on Day 1 and Day 2

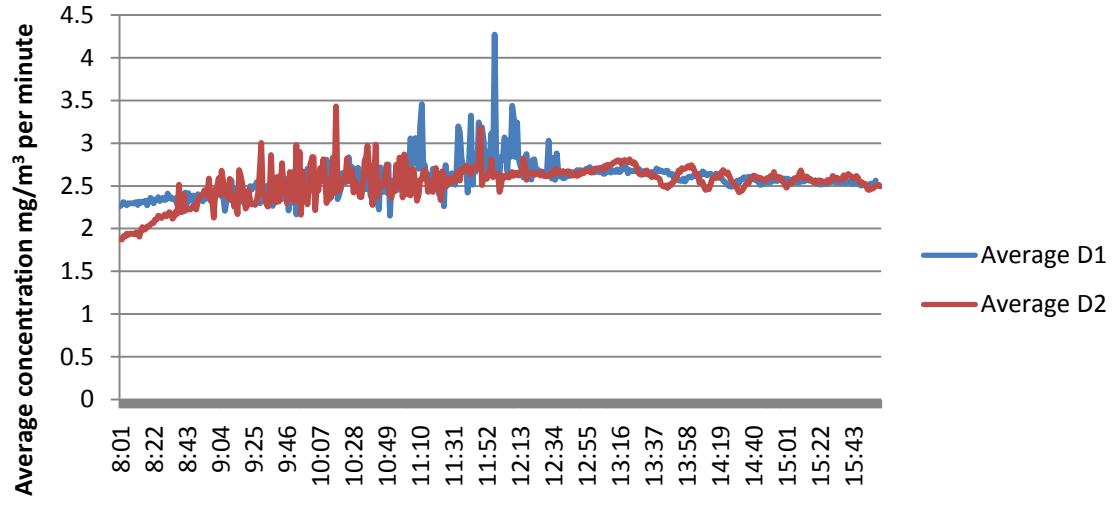

Sampling Time

Figure 5. The measured average PM concentration at sampling point 5 in the vicinity of incineration plant. 


\section{Average concentration recorded at Point 6 on Day 1 and} Day 2

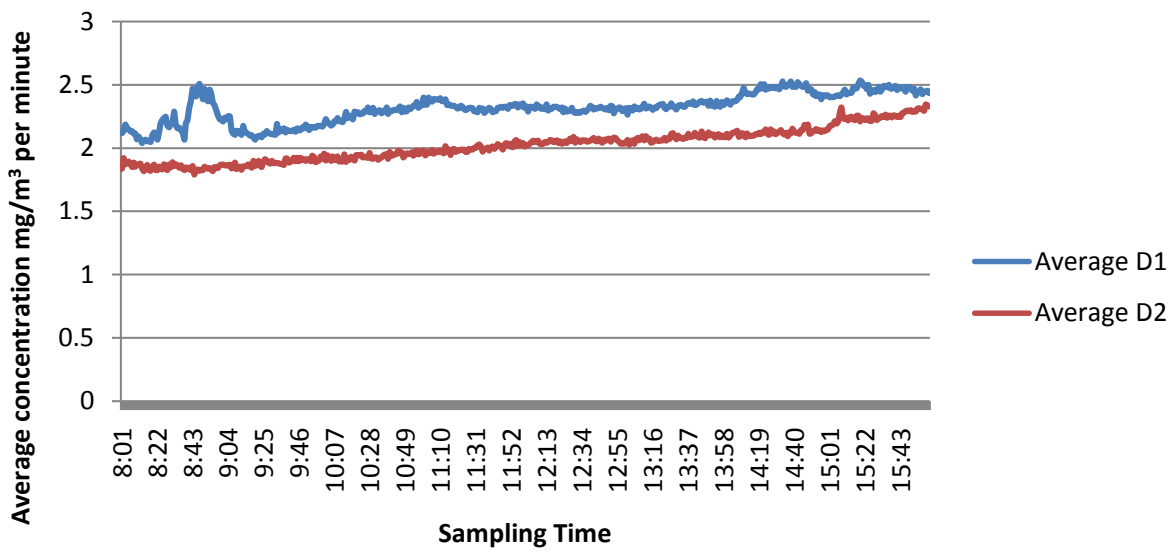

Figure 6. The measured average PM concentration at sampling point 6 in the vicinity of incineration plant.

be linked to random change in wind blow to and from the sampling points from time to time in relation to the incinerator, vehicles, windblown dust re-suspension, varying environmental and metrological factors and other non-point sources thus leading to continuous change in concentration levels [18]. In conjunction with above factors, increase in PM with afternoon hours (especially at point 1, and point 2, of day 2, when the incinerator was not functioning), may be favoured by recirculation of aged mass of air hence the presence of trees in the surrounding of the sampling points and valley which hinder effective dispersion of air [11]. In addition, increase in solar radiation intensity and abundant supply of primary pollutants which enhances photochemical reaction may also lead to high PM concentration [14]. Continuous reduction in particulates trend afterward may be linked to either reduction in heat intensity, short supply of primary pollutants and shut down of non-point sources activities and incinerator.

Particulates pollution is a major concern, not only due to its adverse health effects to human, also because it reduces atmospheric visibility, damage infrastructures and on global scale, PM also have a direct and/or indirect influence the Earth's radiation energy balance and can consequently impact on the global climate change [3]. The $\mathrm{PM}_{10}$ concentration recorded differs partial and temporal with low to high average particulate concentrations, the daily limits and compliance to standards could not be determined hence inability to monitor the sites over 24 hours period. However, it may present potential hazard to human and the environment hence the presence of various toxic elements in the fallout dust. Acute and chronic health effects are related to the in halable $\mathrm{PM}_{10}$ exposure in the urban environment [4] including acute respiratory related conditions (asthma, acute bronchitis, running nose) cerebrovascular disease (stroke), respiratory diseases, cardiopulmonary disorders, ischemic heart disease [19], damage of vital organs such as kidneys, liver and gastrointestinal system [20], different cancer, mortality and reduction in life expectancy, admission in hospitals and regular health 
care visit due to respiratory and heart diseases [3] [4]. The overall national data of Health Information Report 2009-2013 of Ministry of Health and Social Services indicates related respiratory diseases diagnosis, which are one of the major effect of particulate pollutants, to be on increase over those years and the top leading cause of morbidity in children age 0 - 17 years and second amongst patient aged $>17$ treated in outpatient department in all facilities country wide [21].

Similar to dust, PM suspended in the atmosphere leads to visibility degradation. The $\mathrm{PM}_{10}$ particularly $\mathrm{PM}_{2.5}$, a subset of $\mathrm{PM}_{10}$, have optimum size that absorbs and scatter light with wavelength in visible range due to their diameter being similar to that of light wavelength thereby reducing visibility. Continuous emission of gases into the atmosphere may even leads to high visibility degradation. As studies affirmed that secondary particulates that are formed in the atmosphere from primary gases contributes significantly to visibility impairment in polluted areas [22]. Particulates matters tend to soils cities buildings, acidic particles deteriorate artworks thereby diminish the artistic appearance and lifespan and alkaline particles damages painted surfaces.

The particulate matters influence the climate change directly (through scattering and absorption of solar radiation) and indirectly. The particulates especially, from anthropogenic sources which are often concentrated in the lower atmosphere, absorbs the incident light from the sun, and convert them to thermal energy, thereby producing an overall warming of the earth's system [22]. Absorbing particulates may also reduce heat convection and contribute to cloud re-evaporation, thereby disturbing the hydrological cycle [23].

\subsection{Levels of Fallout Dust at Selected Areas}

The fall out rate per day for all the points in sample 1 were in compliance to the standards, all below the American $1200 \mathrm{mg} / \mathrm{m}^{2} /$ day, German $1300 \mathrm{mg} / \mathrm{m}^{2} /$ day and South African $600 \mathrm{mg} / \mathrm{m}^{2} /$ day in residential area and between $600<\mathrm{D}<1200 \mathrm{mg} / \mathrm{m}^{2} /$ day commercial and industrial area standards [24], except for sampling point 2 whose fallout rate, $999.1 \mathrm{mg} / \mathrm{m}^{2} /$ day, exceeded the South African standards for residential area as indicated in Table 2. Unlike the daily fallout rate in sample 2, all points exceeded the German, South African standards for residential area and American standards, the highest fallout rate of $1839.3 \mathrm{mg} / \mathrm{m}^{2} /$ day being recorded at point 4 and the lowest 711.0 $\mathrm{mg} / \mathrm{m}^{2} /$ day at point 2 . A great variation in fallout rate is observable between sample 1 and sample 2 over the two successive weeks of sampling whereby the daily dust concentration increased drastically with an exception to point 2 where fall out rate dropped by $29 \%$. The variation may be due to variation in weather pattern such as wind speed

Table 2. Particle concentrations over sampling period of two weeks concentration $\left(\mathrm{mg} / \mathrm{m}^{2} /\right.$ day).

\begin{tabular}{ccccccc}
\hline Sample & Point 1 & Point 2 & Point 3 & Point 4 & Point 5 & Point 6 \\
\hline 1 & 254.8 & $\mathbf{9 9 9 . 1}$ & $\mathbf{2 0 1 . 3}$ & 419.2 & 249.3 & 487.5 \\
2 & 1748.8 & $\mathbf{7 1 1 . 0}$ & 1423.8 & 1839.3 & 1675.0 & 1531.0 \\
Average & 1001.8 & $\mathbf{8 5 5 . 1}$ & 812.6 & 1129.3 & 962.2 & 1009.3 \\
\hline
\end{tabular}


and wind direction as well as other human activities carried out in the vicinity of the sampling point, though they were not considered in the study.

There is a good correlation between dust pollution and effects on human health and degradation of the environment. Inhalation of dust even at low levels below the set fallout dust standards for a prolonged period of time may lead to the so called "dust overload" in the lungs which may be a precursor to the formation of tumours, even for substances which have previously been regarded as relatively innocuous [25]. The health risks associated with dust depends on the type of dust on the basis of physical, chemical and mineralogical characteristics, which will determine its toxicological properties, and the possible harm it may cause to health is mostly determined by the atmospheric dust concentration and the time of exposure. The dust concentration at all six sites may present potential health hazard to the residing population because the 30 days average concentration have exceeded the South African Standards for residential area. Comparing with international standards it is highly likely that harmful health effects are being experienced by long-term exposure to the fall out dust in these areas. Dust provides a good surface area for chemical reactions, thus exposure to it may present some toxicological effects. High levels of dust may also result in impairment in visibility [22].

\subsection{Elemental Analysis}

The XRF analysis revealed two distinct groups of elemental composition of fallout dust. The fallout dust collected consisted of both crustal and toxic elements (Table 3). Similar to other studies [26] [27] crustal elements had the highest concentration (and a decreasing order of concentration from $\mathrm{Si}, \mathrm{K}, \mathrm{Fe}, \mathrm{Ti}, \mathrm{Ca}, \mathrm{Al}$ and $\mathrm{P}$ ) compared to toxic elements although their levels were also high and varied from point of sampling. Crustal elements are naturally present in the ambient environment and their concentration in the air can be as a result of bounce of (re-suspension of dust as a result of wind blow for instance) rather than emission of very fine particles from the soil [28]. Toxic elements such as $\mathrm{Mn}, \mathrm{Zn}, \mathrm{Cr}$, and $\mathrm{V}$ had the highest concentration than $\mathrm{Sr}, \mathrm{Pb} \mathrm{Ni}$. No $\mathrm{Mn}$ and $\mathrm{Zn}$ were detected in the second sample at point 3,4 and 5. Nickel could only be observed at point 1 , with concentration of 74 and 76 in sample 1 and 2 respectively, whereas lead $(\mathrm{Pb})$ could not be detected at point 3 and point 4 in any of the two sampling sessions. Element such as Lead is found in very trace amount in the soil and it is emitted mainly from anthropogenic sources [28].

Nickel is a toxic element and a potential source of cancer for the local population. Exposure to lead, particularly young children may lead to profound and irreversible cerebral and nervous system effects particularly in children. Whereas in adults, exposure to lead can cause long-term harms including kidney damage, and increased risks of high blood pressure and exposure of pregnant women can cause miscarriage, stillbirth and minor malformation [29]. Elemental composition of metals varied according to location, and domestic and industrial activities in the vicinity of the sampling location where as high concentrations are found at sampling location in the vicinity of the pollution source as per study conducted in South Africa [12]. Sampling points 1, which is 
Table 3. Elemental composition of fallout dust.

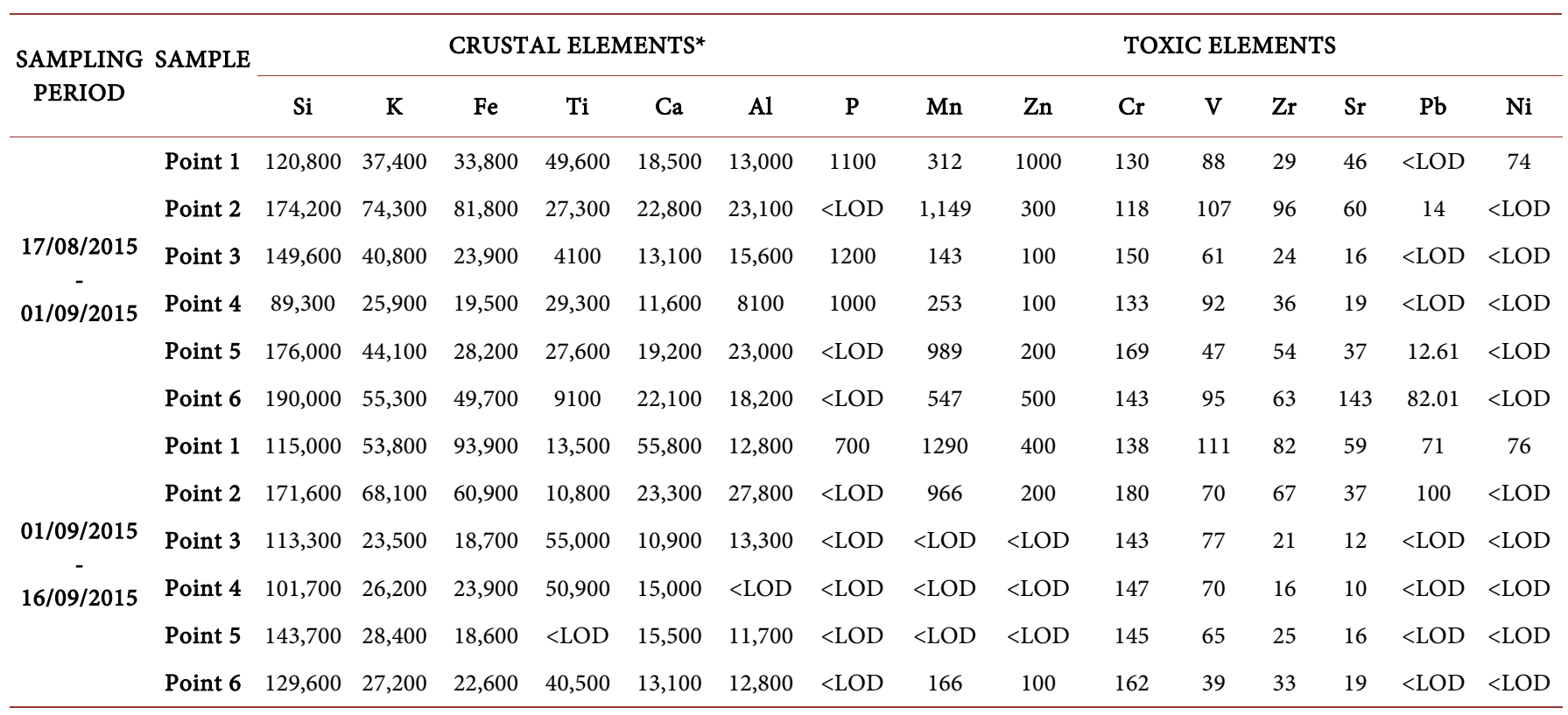

${ }^{*}$ Concentration converted from percentage using the formula: $1 \%=10,000 \mathrm{ppm}, 1 \mathrm{ppm}=1,000,000 \mu \mathrm{g} / \mathrm{m}^{3},{ }^{*}<\mathrm{LOD}$-the elemental composition concentration is below Limit of Detection.

the closest to the incinerator, had the highest concentration of toxic elements followed by point 2 , the second closest to the incinerator and then point 6 which is in industrial area and point 4 , in institutional area had the lowest. On average toxic elements were concentrated in a decreasing order of point $1>2>6>5>3>4$.

\section{Conclusion}

Real time measurement in conjunction with fallout dust sampling is an effective tool to determine the particulate real-time, variation and the chemical composition of the dust that individuals inhale so to make an estimate on the health impacts that are most likely to occur in their residing areas. No positive correlation could be observed between the eight hours average particulate concentration and daily fallout rate. Some of the areas which recorded high fallout dust per day had lower eight hours average concentration. Therefore, there is a need to conduct real-time monitoring over a period of 30 days in conjunction with fallout dust collection to determine whether there is a relationship between the two parameters. Majority of the real time results indicates a rise in particulates with time, reaching highest peak during afternoon hours, though few mornings peak could also be observed especially at Point 4 and 6. The XRF analysis gave a clear indication of the chemical elements in fallout dust. Out of the two elemental categories (toxic and crustal elements) toxic elements: $\mathrm{Mn}, \mathrm{Zn}, \mathrm{Cr}, \mathrm{V}, \mathrm{Zr}, \mathrm{Sr}, \mathrm{Pb}$, and Ni were measured in order of decreasing abundance so did $\mathrm{Si}, \mathrm{K}, \mathrm{Fe}, \mathrm{Ti}, \mathrm{Ca}, \mathrm{Al}$ and $\mathrm{P}$ crustal elements. Those toxic elements can lead to a variety of acute and chronic health effects on individual depending on their susceptibility. Points in the close proximity to incinerator (point 1 and 2), in industrial areas and in the direction of the most prevailing wind recorded the highest concentration of toxic elements. Thus there is a need to re- 
gulate air polluting activities, control and monitor the pollution emission rate of the known stationary source, and as a part of strategic plan, the city of Windhoek in consultation with Ministry of Health needs to develop a long term monitoring strategy for the town, while follow-up study on association between PM concentration and Windhoek resident health is recommended.

\section{Acknowledgements}

The authors acknowledge the Environmental Health Science Programme-Namibia University of Science and technology (NUST) and the Ministry of Mines and Energy for analysis of samples. Financial support by the National Commission on Research, Science and Technology (NCRST), and permission to conduct research granted by the City of Windhoek is also acknowledged.

\section{References}

[1] Kamal, A., et al. (2013) Principle Component Analysis of Flue Gas Exhaust and Health Risk Estimates for the Population around a Functional Incinerator in the Vicinity of Rawalpindi Pakistan. Arabian Journal of Chemistry, Online. https://doi.org/10.1016/j.arabjc.2013.08.006

[2] Ostro, B. (2004) Outdoor Air Pollution-Assessing the Environmental Burden of Disease at National and Local Levels. World Health Organization, Geneva, Environmental Burden of Disease Series No. 5.

[3] Tasic, M., et al. (2008) Assessment of Air Quality in an Urban Area of Belgrade, Serbia. Environmental Technologies. Burcu Ozkaraova Gungor, E., Ed., I-Tech Education and Publishing, Vienna.

http://www.intechopen.com/books/environmental technologies/assessment of air quality in an urban area of belgrade serbia

[4] Pope, C.A. and Dockery, D.W. (2006) Health Effects of Fine Particulate Air Pollution: Lines that Connect. Journal of the Air \& Waste Management Association, 56, 709-742. https://doi.org/10.1080/10473289.2006.10464485

[5] Simoni, M., et al. (2015) Adverse Effects of Outdoor Pollution in the Elderly. Journal of Thoracic Disease, 7, 34-45.

[6] IARC (2013) Outdoor Air Pollution a Leading Environmental Cause of Cancer Deaths. International Agency for Research on Cancer, Press Release, Lyon.

[7] WHO (2006) Guidelines WHO Air Quality Guidelines for Particulate Matter, Ozone, Nitrogen Dioxide and Sulphur Dioxide. WHO, Geneva.

[8] Kgabi, N. (2010) An Assessment of Common Atmospheric Particulate Matter Sampling and Toxic Metal Analysis Methods. African Journal of Environmental Science and Technology, 4, 718-728.

[9] Baldasano, J.M. (2011) An Annual Assessment of Air Quality with the CALIOPE Modelling System over Spain. Science of the Total Environment, 409, 2163-2178. https://doi.org/10.1016/j.scitotenv.2011.01.041

[10] Chaloulakou, A., et al. (2002) Comparison of Indoor and Outdoor Concentrations of CO at a Public School. Evaluation of an Indoor Air Quality Model. Atmospheric Environment, 36, 1769-1781. https://doi.org/10.1016/S1352-2310(02)00151-6

[11] Aher, S.B. (2014) Assessment of Ambient Air Quality of India Using Air Quality Index. In- 
dian Journal of Environmental Sciences, 18, 65-72.

[12] Kgabi, N. (2012) Composition of Inhalable Atmospheric Particulates in Rustenburg, South Africa. British Journal of Environment \& Climate Change, 2, 58-72. https://doi.org/10.9734/BJECC/2012/833

[13] US EPA (2003) Particulate Matter (PM) Pollution: Particulate Matter Basic. https://www.epa.gov/pm-pollution/particulate-matter-pm-basics

[14] Berthouex, P. and Brown, L.C. (2013) Pollution Prevention Control: Human Health and Environmental Quality. http://bookboon.com/en/pollution-prevention-and-control-ebook

[15] Kgabi, N., Shitaatala, E. and Izaaks, C. (2012) Morphological Analysis of Fallout Dust in Windhoek, Namibia. Journal of Chemical, Biological and Physical Sciences, 2, 2201-2209.

[16] Gold, J., Muller, A. and Mitlin, D. (2001) The Principles of Local Agenda 21 in Windhoek: Collective Action and the Urban Poor. Working Paper Series on Urban Environmental Action Plans and Local Agenda 21, Paper No. 9.

[17] American Society for Testing and Materials: Standard Test Method for Collections and Measurement of Dustfall (Settleable Particulate Matter), ASTM D1739-98, 2004.

[18] Mansour, A., et al. (2015) Characterization and Elemental Composition of Atmospheric Aerosol Loads during Springtime Dust Storm in Western Saudi Arabia. Aerosol and Air Quality Research, 15, 440-453. https://doi.org/10.4209/aaqr.2014.06.0110

[19] Zhao, S., Chen, L., Li, Y., Xing, Z. and Du, K. (2015) Summertime Spatial Variations in Atmospheric Particulate Matter and Its Chemical Components in Different Functional Areas of Xiamen, China. Atmosphere, 6, 234-254. https://doi.org/10.3390/atmos6030234

[20] Fernandez, X.G.A., Sicat, L.V. and David, M.E.D. (2011) Analysis of the Ambient Air Quality of Tarlac City: Baseline Data for Environmental Management Plan. Journal of Materials Science and Engineering A, 1, 64-70.

[21] MoHSS (2014) Health Information Report 2013. Ministry of Health and Social Services, Republic of Namibia.

[22] Jimoda, L.A. (2012) Effects of Particulate Matter on Human Health, the Ecosystem, Climate and Materials: A Review. Series. Working and Living Environmental Protection, 9, 27-44.

[23] Ackerman, A.S., Toon, O.B., Stevens, D.E., Heymsfield, A.J., Ramanathan, V. and Welton, E.J. (2000) Reduction of Tropical Cloudiness by Soot. Science, 288, 1042-1047. https://doi.org/10.1126/science.288.5468.1042

[24] Mondi (2012) Richard Fugitive Dust Plan.

[25] Morrow, P.E. (1992) Dust Overloading of the Lungs: Update and Appraisal. Toxicology and Applied Pharmacology, 113, 1-12. https://doi.org/10.1016/0041-008X(92)90002-A

[26] Hamatui, N., Kgabi, N., Naidoo, R. and Izaaks, C.D. (2014) Characterization of Fallout Dust from a Charcoal Processing Plant. European Journal of Scientific Research, 127, 3945.

[27] Gajghate, D.G., Pipalatkar, P. and Khaparde, V.V. (2012) Atmospheric Concentration of Trace Elements, Dry Deposition Fluxes and Sources Apportionment Study in Mumbai.

[28] Melas, D. and Syrakov, D. (2012) Air Pollution Processes in Regional Scale. Earth and Environmental Science, 30, 1-10.

[29] WHO (2016) Media Centre: Lead Poisoning and Health-Facts Sheet. http://www.who.int/mediacentre/factsheets/fs379/en/ 